\title{
Highly Efficient Metal-Free Nitrogen-Doped Nanocarbons with Unexpected Active Sites for Aerobic Catalytic Reactions
}

Yangming Lin, ${ }^{*, \dagger}$, Zigeng Liu, ${ }^{\ddagger}$ Yiming Niu, $^{\dagger}$ Bingsen Zhang, ${ }^{\dagger}$ Q Qing Lu, ${ }^{\ddagger}$ Shuchang Wu, ${ }^{\dagger}$ Gabriele Centi, ${ }^{\S}$ Siglinda Perathoner, ${ }^{\S}$ Saskia Heumann, ${ }^{\ddagger}$ Linhui Yu, ${ }^{*},+, \|^{\prime}$ and Dang Sheng Su ${ }^{\dagger, \perp}$

${ }^{\dagger}$ Institute of Metal Research, Chinese Academy of Sciences, 72 Wenhua Road, Shenyang 110016, P.R. China

${ }^{\ddagger}$ Max Planck Institute for Chemical Energy Conversion, Stiftstrasse 34-36, Mülheim an der Ruhr 45470, Germany

${ }^{\S}$ University of Messina, V.le F. Stagno D’Alcontres 31, 98166 Messina, Italy

"Fuzhou University, Fuzhou 350002, P.R. China

${ }^{\perp}$ Department of Inorganic Chemistry, Fritz Haber Institute of the Max Planck Society, Faradayweg 4-6, Berlin 14195, Germany

\section{Supporting Information}

ABSTRACT: Nitrogen (N)-doped nanocarbons (NDN) as metal-free catalysts have elicited considerable attention toward selective oxidation of alcohols with easily oxidizable groups to aldehydes in the past few years. However, finding a new NDN catalytic material that can meet the requirement of the feasibility on the aerobic catalytics for other complicated alcohols is a big challenge. The real active sites

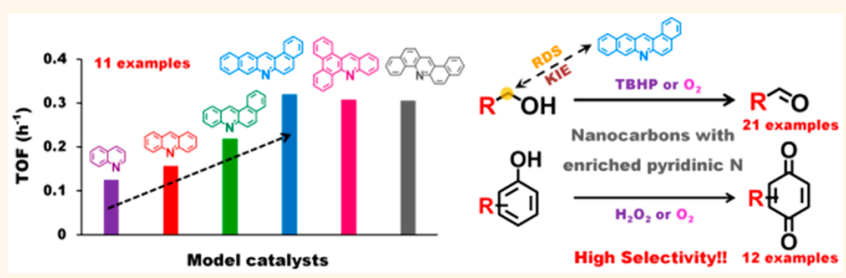
and the corresponding mechanisms on NDN are still unambiguous because of inevitable coexistence of diverse edge sites and $\mathrm{N}$ species based on recently reported doping methods. Here, four NDN catalysts with enriched pyridinic $\mathbf{N}$ species and without any graphitic $\mathrm{N}$ species are simply fabricated via a chemical-vapor-deposition-like method. The results of X-ray photoelectron spectroscopy and X-ray absorption near-edge structure spectra suggest that the dominating $\mathrm{N}$ species on NDN are pyridinic $\mathrm{N}$. It is demonstrated that NDN catalysts perform impressive reactivity for aerobic oxidation of complicated alcohols at an atmospheric pressure. Eleven kinds of aromatic molecules with single $\mathbf{N}$ species and tunable $\pi$ conjugation systems are used as model catalysts to experimentally identify the actual role of each $\mathrm{N}$ species at a real molecular level. It is suggested that pyridinic $\mathrm{N}$ species play an unexpected role in catalytic reactions. Neighboring carbon atoms in pyridinic $\mathrm{N}$ species are responsible for facilitating the rate-determining step process clarified by kinetic isotope effects, in situ nuclear magnetic resonance, in situ attenuated total reflectance infrared, and theoretical calculation. Moreover, NDN catalysts exhibit a good catalytic feasibility on the synthesis of important natural products (e.g., intermediates of vitamin E and K3) from phenol oxidation.

KEYWORDS: nanodiamond, carbon materials, metal-free, nitrogen-doped, catalysis, model catalyst, kinetic isotope effect

atalytic oxidation of alcohols to value-added products is an important reaction in catalytic synthesis. ${ }^{1,2}$ Metal-based materials are the most common catalysts for highlighting that reaction. Although doped nanocarbon materials, such as nitrogen-doped nanocarbon (NDN) or phosphorus-doped carbon, as the representative metal-free catalysts, have shown promising ability in the catalytic oxidation of alcohols with easily oxidizable functionalities using $\mathrm{O}_{2}$ as oxidant, the validity for other complicated alcohols (e.g., unsaturated, heterocyclic, and aliphatic alcohols) has been rarely revealed due to the inactivity of the reported carbon catalysts. $^{3,4}$ This inevitably hinders their practicality. It can be expected that finding an efficient and green heterogeneous nanocatalyst to enable aerobic oxidation of diverse alcohols at an atmospheric pressure is highly desired.
Moreover, understanding the detailed activation process of the alcohols on metal-free catalysts is still a big challenge. Some important achievements on the investigation of active sites have been made using various research means; however, difficulties still focus on understanding the intrinsic mechanism of NDN catalysts. ${ }^{3,5}$ The reasons are (1) the inevitable coexistence of diverse $\mathrm{N}$ functional groups at the carbon edge (pyrrolic, $\mathrm{O}=\mathrm{C}-\mathrm{NH}$, pyridinic, $-\mathrm{NH}_{2}$ etc.) during the preparation process and (2) multifarious edge defect (heteroatom-free) configurations. Taking aerobic oxidation of the alcohols as an example, graphitic N (GN) species have

Received: July 25, 2019

Accepted: November 25, 2019

Published: November 25, 2019 
been proposed to be the most common active sites, whereas the roles of other $\mathrm{N}$ species in the reaction have been ignored. ${ }^{3}$ The interaction at the interface between the catalyst and the substrate remains elusive and controversial. The preparation of NDN with isolated $\mathrm{N}$ species is the best way to directly determine the real role of each $\mathrm{N}$ species in the reactions, but it is still an open question due to deficient-controlled doping characteristics based on recently established experimental methods. It is therefore necessary to find other effective means to identify the true active sites and to study the intrinsic mechanism.

In this report, we develop a class of NDN catalysts with enriched pyridinic $\mathrm{N}$ by using three nanocarbon materials (bucky nanodiamond (BND), carbon nanotubes (CNTs), and nitrogen-doped onion-like carbon (OLC)) as starting materials (Scheme 1 and Figure S1). Three NDN including nitrogen-

Scheme 1. Schematic Illustration of the Fabrication of Nitrogen-Doped Nanocarbon Samples ${ }^{a}$

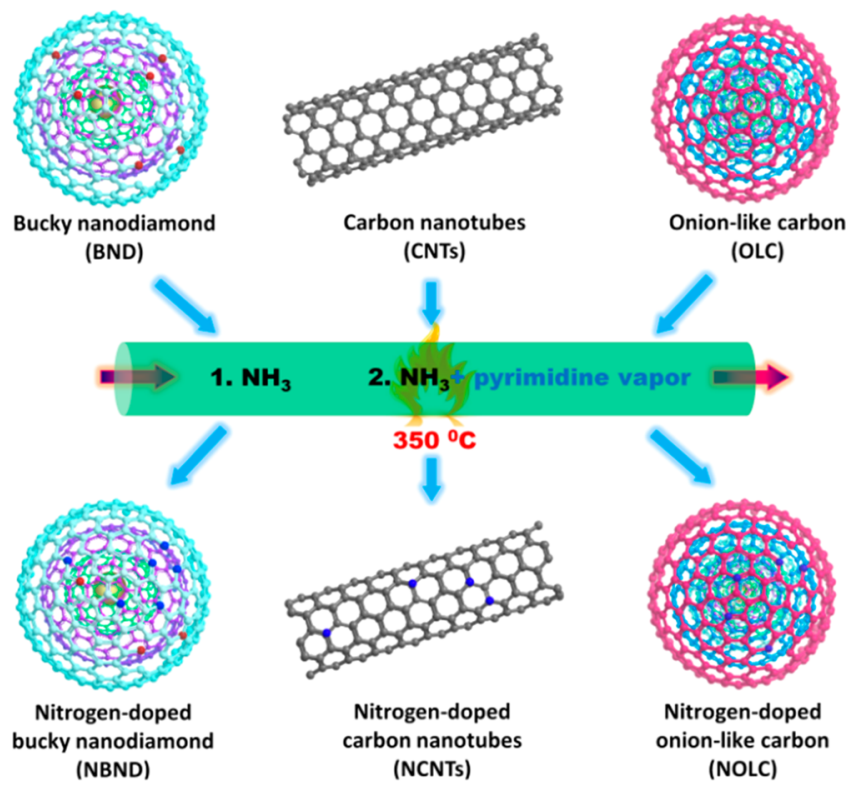

${ }^{a}$ For CNTs, a single-walled structure was used as an ideal model. Here, blue is $\mathrm{N}$, and red is $\mathrm{O}$.

doped bucky nanodiamond (NBND), nitrogen-doped carbon nanotubes (NCNTs), and nitrogen-doped onion-like carbon (NOLC) were prepared via a chemical vapor deposition (CVD)-like method in which both the pyrimidine vapor and ammonia gas were used as the nitrogen precursors at a relatively low calcination temperature. The surface chemical information on NDN was revealed by X-ray photoelectron spectroscopy (XPS) and X-ray absorption near-edge structure (XANES) measurements. Such catalysts have been demonstrated to possess promising capabilities for the oxidation of complicated alcohols (e.g., cinnamic alcohol, 21 examples) and phenols (12 examples) with $\mathrm{O}_{2}$ and $t$-butylhydroperoxide (TBHP) or $\mathrm{H}_{2} \mathrm{O}_{2}$ as oxidants. We then directly demonstrate the potential roles and the activation mechanisms of typical $\mathrm{N}$ species by means of aromatic molecules with single $\mathrm{N}$ species as model catalysts. With the assistance of some in situ measurements and theoretical calculation, some in-depth insights into the active sites and the activation processes of carbon catalysts for substrates are provided.

\section{RESULTS AND DISCUSSION}

Materials Characterization. First, the detailed surface compositions of three NDN are summarized in Figure $1 \mathrm{a}, \mathrm{b}$. The $\mathrm{N}$ and $\mathrm{O}$ species mainly contain pyridinic $\mathrm{N}(398.3 \mathrm{eV})$, lactam N/amide $\mathrm{N}(399.1 \mathrm{eV})$, pyrrolic $\mathrm{N}(400.2 \mathrm{eV})$, pyridine $\mathrm{N}$-oxide $(402-405 \mathrm{eV})$, quinines/pyridone $(530.4 \mathrm{eV})$, unsaturated $\mathrm{C}=\mathrm{O}(531.6 \mathrm{eV})$, ether/anhydride $\mathrm{C}-\mathrm{O}(532.7$ $\mathrm{eV})$, phenolic $\mathrm{C}-\mathrm{OH}(533.7 \mathrm{eV})$, and trace adsorbed $\mathrm{H}_{2} \mathrm{O}$ $(535.4 \mathrm{eV}){ }^{6,7}$ The proportion of pyridinic $\mathrm{N}$ species among all the $\mathrm{N}$ functionalities is around $53.8-62.8 \%$. No obvious GN species can be observed on these three catalysts. Figure 1c shows the normalized C K-edge XANES spectra of representative NBND and the referenced BND. The spectra of these two samples include two main features located around 285 and $291 \mathrm{eV}$, which are assigned to $\pi^{*}$ antibonding and $\sigma^{*}$ antibonding orbitals at the $\operatorname{sp}^{2}(\mathrm{C}=\mathrm{C}$ band in the ring) site from the $C$ 1s level, respectively. ${ }^{8}$ It should be pointed out that, compared to BND, an additional peak of NBND can be observed at $287.2 \mathrm{eV}, 9$, which can be attributed to a $\sigma^{*}$ bond of $\mathrm{C}-\mathrm{N}$. No other carbon-nitrogen species can be observed in the $\mathrm{C}$ K-edge XANES spectra. As displayed in N K-edge XANES spectra (Figure 1d), NBND shows a pronounced $\pi^{*}$ bond of pyridinic $\mathrm{C}-\mathrm{N}$ (at $397.5 \mathrm{eV}$ ) and a relatively weaker $\pi^{*}$ bond of amino/lactam-type (at $398.8 \mathrm{eV}$ ), suggesting the main $\mathrm{N}$ species over NBND are pyridinic N. ${ }^{9}$ The peak appearing at $406.0 \mathrm{eV}$ is regarded as the general $\sigma^{*}$ transition state from the $\mathrm{N} 1 \mathrm{~s}$ core level to the $\mathrm{C}-\mathrm{N}$. In addition, $\mathrm{N}$ species have been demonstrated to be homogeneously distributed on the surface of NBND by using high-angle annular dark-field scanning transmission electron microscopy energy dispersive X-ray spectrometry (HAADF-STEM-EDX) (Figure 1f). The introduction of $\mathrm{N}$ species does not obviously change the original surface morphology of BND (Figure 1e and Figure S1).

Activity Evaluation. Catalytic oxidation of benzyl alcohol $\left(\mathrm{Ph}-\mathrm{CH}_{2} \mathrm{OH}\right)$ to benzylaldehyde (Ph-CHO) was then used as a probe in the reaction to evaluate the potential reactivity of different NDN. As listed in Table 1, three undoped nanocarbons, including BND, CNTs, and OLC, offer low conversion of the substrate (entries 2, 4, and 6) using TBHP as the oxidant. After modification by the $\mathrm{N}$ species, all three NDN with enriched pyridinic $\mathrm{N}$ show enhanced catalytic performance (entries 3, 5, and 7). It appears that the improved activity originates from the pyridinic $\mathrm{N}$ that has been widely highlighted in other reactions. ${ }^{10}$ To confirm that, we use BND as a starting material to prepare the NBND-1 catalyst with a lower content of pyridinic $\mathrm{N}(0.37$ atom \%) relative to that of the NBND catalyst with 0.88 atom \%. Their surface $\mathrm{N}$ concentrations and similar surface areas are shown in Figure S2. As displayed in Table 1, the results of activity evaluation indicate that NBND-1 shows the conversion rate of $13.8 \%$, which is lower than that of the NBND catalyst (32.5\%), suggesting the positive role of the content of pyridinic $\mathrm{N}$ in improving the performance. In other words, pyridinic $\mathrm{N}$ species are advantageous to accelerate alcohol oxidation, whereas lactam/amide $\mathrm{N}$, pyrrolic $\mathrm{N}$, and pyridine $\mathrm{N}$-oxide species do not show an obviously positive role because their concentrations could not well correlate with the activity. As mentioned above, GN species were proposed to be the most common active sites in that catalytic reaction. ${ }^{3}$ Herein, NOBND with a total concentration of pyridinic $\mathrm{N}$ and GN species $(0.79$ atom \%) close to that of the NBND catalyst 

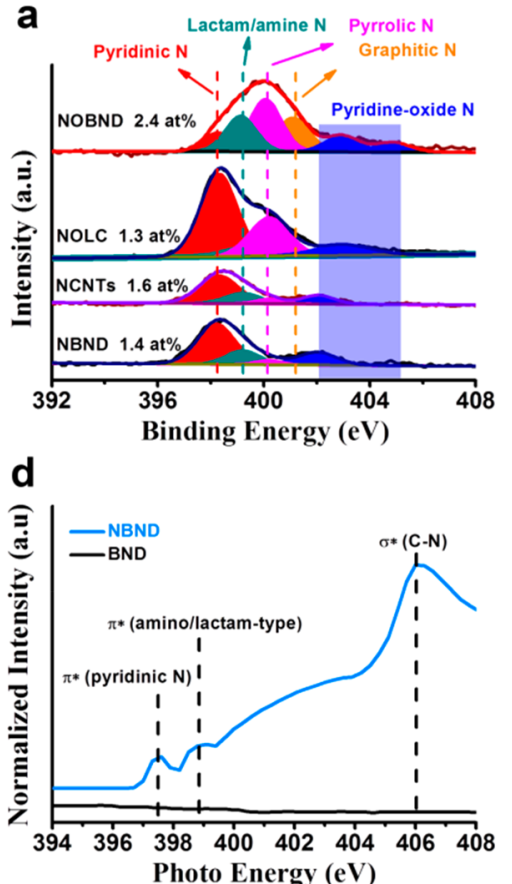

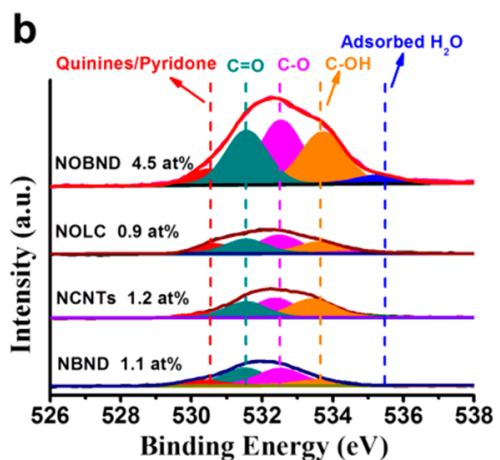

e

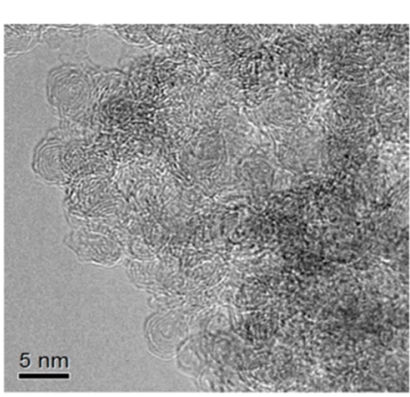

C

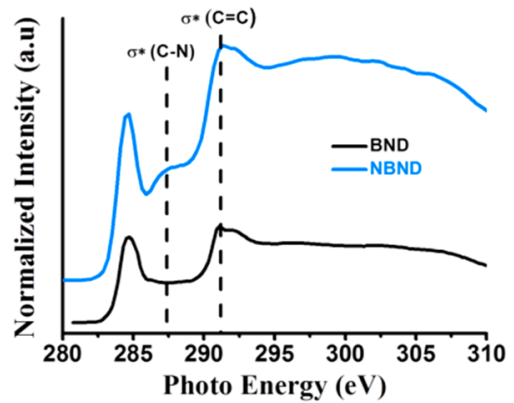

f

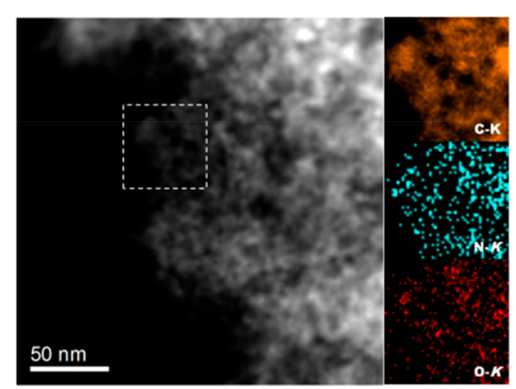

Figure 1. Surface composition and structural characterization of various NDN catalysts. (a) XPS N 1s and (b) O 1s spectra of NBND, NCNTs, NOLC, and NOBND catalysts. The XPS spectra are divided by fitting the peak maximum within $\pm 0.1 \mathrm{eV}$. The value of the mixed Gaussian-Lorentzian is maintained at $30 \%$. XANES spectra (incident angle $\theta=45^{\circ}$ ) of representative NBND and BND at $(c) C$ K-edge and (d) N K-edge. (e) High-resolution transmission electron microscopy and (f) HAADF-STEM-EDX mapping images of NBND. Colors in elemental mapping images are orange for $\mathrm{C}$, cyan for $\mathrm{N}$, and red for $\mathrm{O}$.

Table 1. Selective Oxidation of $\mathrm{Ph}-\mathrm{CH}_{2} \mathrm{OH}$ by Various NDN Catalysts ${ }^{a}$

\begin{tabular}{|c|c|c|c|c|c|c|c|}
\hline entry & catalyst & conversion (\%) & selectivity (\%) & entry & catalyst & conversion (\%) & selectivity (\%) \\
\hline 1 & & 1.3 & 99.3 & $10^{b}$ & NBND & 88.5 & $>99$ \\
\hline 2 & $\mathrm{BND}$ & 4.5 & 98.2 & $11^{c}$ & NBND & 87.9 & $>99$ \\
\hline 3 & NBND & 32.5 & $>99$ & $12^{d}$ & 5 wt $\% \mathrm{Ru} / \mathrm{C}$ & 22 & 60 \\
\hline 4 & CNTs & 3.1 & 99.2 & $13^{e}$ & $\mathrm{Au} / \mathrm{MO}_{\mathrm{X}} / \mathrm{PF}_{6}$ & $\sim 89$ & $\sim 89$ \\
\hline 5 & NCNTs & 13.8 & $>99$ & $14^{f}$ & $\mathrm{Co} / \mathrm{VPO}$ & 53 & 93 \\
\hline 6 & OLC & 10.2 & 95.7 & $15^{g}$ & $0.1 \% \mathrm{Fe} / \mathrm{NBND}$ & 32.1 & $>99$ \\
\hline 7 & NOLC & 21.1 & $>99$ & $16^{h}$ & $0.1 \% \mathrm{Cr} / \mathrm{NBND}$ & 33.8 & $>99$ \\
\hline 8 & NBND-1 & 13.8 & $>99$ & $17^{i}$ & NBND & 93.4 & $>99$ \\
\hline 9 & NOBND & 33.4 & $>99$ & $18^{j}$ & NBND & 90.3 & 98.4 \\
\hline
\end{tabular}

${ }^{a}$ Reaction condition: $10 \mathrm{mg}$ of catalyst, $2.0 \mathrm{mmol}$ benzyl alcohol $\left(\mathrm{Ph}-\mathrm{CH}_{2} \mathrm{OH}\right)$ substrate, $2 \mathrm{mmol} 65 \mathrm{wt} \% \mathrm{TBHP}, 5 \mathrm{~mL}$ of $\mathrm{CH}{ }_{3} \mathrm{CN}(\mathrm{ACN}), 70{ }^{\circ} \mathrm{C}$, $4 \mathrm{~h} .{ }^{b} 24 \mathrm{~h} .{ }^{c} 50{ }^{\circ} \mathrm{C}, 42 \mathrm{~h}$. ${ }^{d}$ From ref $11,1.1 \mathrm{mmol}$ substrate, $20 \mathrm{mg}$ of catalyst, $120{ }^{\circ} \mathrm{C}, 3 \mathrm{~h}, \mathrm{O}_{2}$ as oxidant. ${ }^{e}$ From ref $12,75 \mathrm{mg}$ of catalyst, $30 \mathrm{mmol}$ substrate, $45 \mathrm{mmol}$ TBHP, $125{ }^{\circ} \mathrm{C}, 6 \mathrm{~h} .{ }^{f_{\mathrm{F}}}$ From ref $13,10 \mathrm{mg}$ of catalyst, $10 \mathrm{mmol}$ substrate, $10 \mathrm{mmol} \mathrm{TBHP}, 90{ }^{\circ} \mathrm{C}, 4 \mathrm{~h} .{ }^{g} \mathrm{Fe}\left(\mathrm{NO}_{3}\right)_{3}$ as precursor, annealed at $573 \mathrm{~K}$ for $1 \mathrm{~h} .{ }^{h} \mathrm{Cr}\left(\mathrm{NO}_{3}\right)_{3} \cdot 9 \mathrm{H}_{2} \mathrm{O}$ as precursor, annealed at $573 \mathrm{~K}$ for $1 \mathrm{~h} .{ }^{i} 0.1 \mathrm{MPa} \mathrm{O}_{2}, 120^{\circ} \mathrm{C}, 10 \mathrm{~mL}$ of ACN, 16 h. ${ }^{j}$ Seventh cycle test under the footnote (i) conditions. Desired product is benzaldehyde (Ph-CHO).

(pyridinic $\mathrm{N}$ of 0.88 atom \%) was additionally obtained (Figure 1a and Table S1). Similar activity results between NBND and NOBND (entries 3 and 9) suggest that both pyridinic $\mathrm{N}$ and $\mathrm{GN}$ species are likely advantageous to accelerate alcohol oxidation. The influence of $\mathrm{C}=\mathrm{O}$ species of NDN catalysts on performance was also comparatively investigated. The concentration of $\mathrm{C}=\mathrm{O}(0.43$ atom \%) over NBND is much less than that of NOBND with 1.21 atom \% (Figure $1 \mathrm{~b}$ and Table S1). Nevertheless, there is no obvious difference in their activities, indicating that the role of $\mathrm{C}=\mathrm{O}$ is not critical. The reactivity of NBND is further improved to $88.5 \%$ along with a decent selectivity by prolonging the reaction time (entry 10). The similar catalytic behavior of NBND can also be achieved at a lower temperature (entry 11). The influence of inherent metal impurities (e.g., Fe $<50$ ppm,
$\mathrm{Cr}<10 \mathrm{ppm}$ ) of catalysts can be excluded by using the comparative experiments (entries 15 and 16). It should be emphasized that NBND shows good catalytic activity and stability when $\mathrm{O}_{2}$ was used as an oxidant (entries 17 and 18) at an atmospheric pressure. The observed excellent performance of NBND is comparable to that of the reported metal supported catalysts (entries 12-14). ${ }^{11-13}$

Mechanism Study. Kinetic isotope effect (KIE), an established experimental technique to study chemical reactions involving protons, was carried out on the NBND catalyst to further understand the reaction mechanism. Specifically, the substitution of hydrogen with deuterium has been implemented extensively due to the large differences in reaction rates originating from the reduced mass differences between the isotopes. ${ }^{14}$ Here, oxidation of $\mathrm{Ph}-\mathrm{CH}_{2} \mathrm{OH}$ to $\mathrm{Ph}-\mathrm{CHO}$ 
a

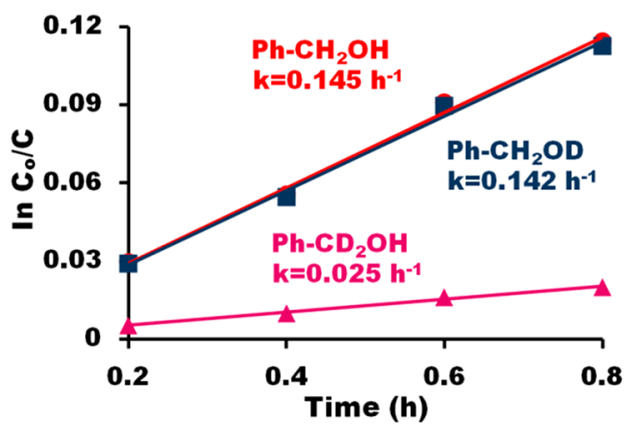

b

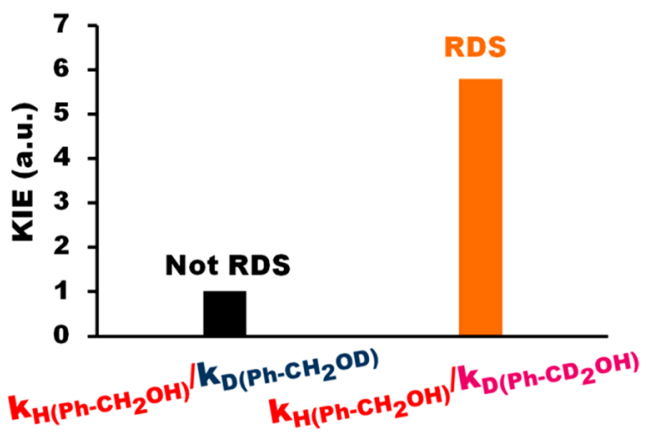

Figure 2. Isotopic kinetic studies for catalyzing $\mathrm{Ph}-\mathrm{CH}_{2} \mathrm{OH}, \mathrm{Ph}-\mathrm{CH}_{2} \mathrm{OD}$, and $\mathrm{Ph}-\mathrm{CD}_{2} \mathrm{OH}$ substrates over NBND catalyst. (a,b) Reaction rates $(k)$ and the corresponding kinetic isotopic effect (KIE) values, respectively. KIE values were calculated with the reaction rates of Ph$\mathrm{CH}_{2} \mathrm{OH}, \mathrm{Ph}-\mathrm{CH}_{2} \mathrm{OD}$, and $\mathrm{Ph}-\mathrm{CD}_{2} \mathrm{OH}$ through the equation $\mathrm{KIE}=k_{\mathrm{H}} / k_{\mathrm{D}}$. To exclude the diffusion effect, all of the reaction rates were collected at $<10 \%$ conversion. Reaction conditions: $10 \mathrm{mg}$ of NBND catalyst, $2.0 \mathrm{mmol} \mathrm{Ph}-\mathrm{CH}_{2} \mathrm{OH}, 0.1 \mathrm{MPa} \mathrm{O}_{2}, 10 \mathrm{~mL} \mathrm{of} \mathrm{CH}_{3} \mathrm{CN}(\mathrm{ACN})$, $120{ }^{\circ} \mathrm{C}$.

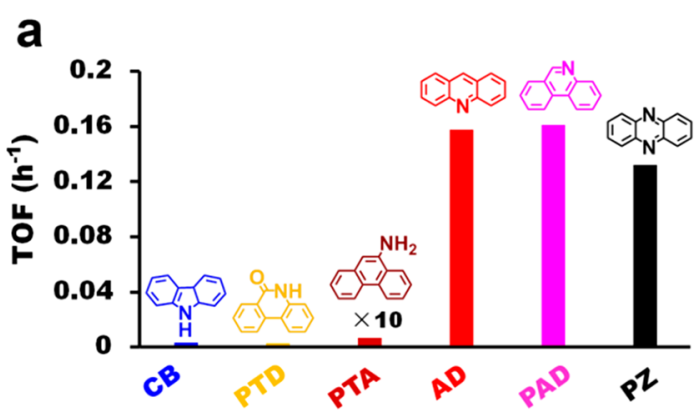

Model catalysts

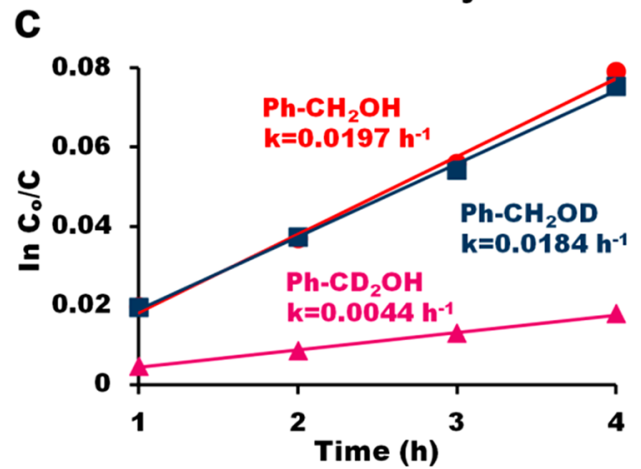

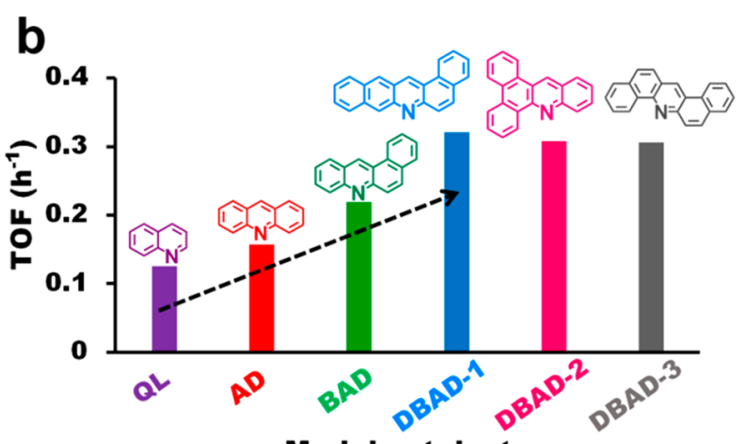

d

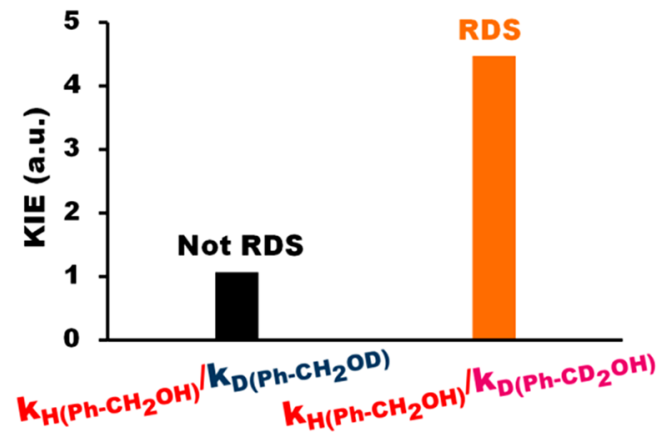

Figure 3. Catalytic activity of various model catalysts with single N species. (a) TOF values of six model catalysts with four kinds of $\mathrm{N}$ species. Here, TOF values of PTA catalysts are multiplied by 10 for better comparison with other catalysts. (b) TOF values of six pyridinic $\mathrm{N}$-containing model catalysts with gradually extended $\pi$-conjugated structure and different structural configurations. (c,d) Reaction rates $(k)$ and KIE values of isotopic kinetic studies of $\mathrm{AD}$ catalyst with single pyridinic $\mathrm{N}$ species toward selective oxidation of various substrates, respectively. Reaction conditions: $0.2 \mathrm{mmol}$ model catalyst, $2.0 \mathrm{mmol} \mathrm{Ph}-\mathrm{CH}_{2} \mathrm{OH}, 2 \mathrm{mmol} \mathrm{TBHP}, 5 \mathrm{~mL} \mathrm{ACN}, 70^{\circ} \mathrm{C}, 4 \mathrm{~h}$.

mainly involves the losses of two protons including $\alpha-\mathrm{H}$ of $-\mathrm{CH}_{2}$ and hydroxylic $\mathrm{H}$ of $\mathrm{Ph}-\mathrm{CH}_{2} \mathrm{OH}$. Therefore, two kinds of isotope-labeled $\mathrm{Ph}-\mathrm{CH}_{2} \mathrm{OD}$ and $\mathrm{Ph}-\mathrm{CD}_{2} \mathrm{OH}$ as substrates were used in the measurement. In Figure $2 \mathrm{a}$, there is a linear relationship between $\ln \left(C_{0} / C\right)$ and the reaction time, indicating that the reaction is first order. ${ }^{15}$ The reaction rate $k$ of $\mathrm{Ph}-\mathrm{CH}_{2} \mathrm{OD}$ is $0.142 \mathrm{~h}^{-1}$, which is similar to that of $\mathrm{Ph}$ $\mathrm{CH}_{2} \mathrm{OH}\left(0.145 \mathrm{~h}^{-1}\right)$ but higher than the value of $\mathrm{Ph}-\mathrm{CD}_{2} \mathrm{OH}$ $\left(0.025 \mathrm{~h}^{-1}\right)$. The KIE values in Figure $2 \mathrm{~b}$ for hydroxylic H/D and $\alpha-\mathrm{H} / \alpha-\mathrm{D}$ are 1.02 and 5.80, respectively, reflecting that the former has a negligible isotope effect, whereas the latter shows a significant primary isotope effect on the $\mathrm{Ph}-\mathrm{CH}_{2} \mathrm{OH}$ oxidation reaction. Furthermore, the primary isotope effect (for $\mathrm{C}-\mathrm{H} / \mathrm{C}-\mathrm{D}$ ) with a high KIE value in this reaction is a direct indicator for the rate-determining step (RDS). ${ }^{16}$ Therefore, it can be concluded that the cleavage of $\alpha-\mathrm{H}$ of $-\mathrm{CH}_{2}$, rather than that of hydroxylic $\mathrm{H}$, is the RDS in Ph$\mathrm{CH}_{2} \mathrm{OH}$ oxidation reaction.

As mentioned above, the incorporation of $\mathrm{N}$ species can significantly improve the catalytic reactivity. To determine which $\mathrm{N}$ species is the real active site, model catalysts with single $\mathrm{N}$ species were applied. Actually, nanocarbons with graphitic structures can be considered as $\mathrm{sp}^{2}$ carbon atoms, with ring configurations, in a two-dimensional sheet structure. $\mathrm{N}$ heteroatoms can generate different kinds of functional groups at the edges of the graphene layers (Scheme S1a). In 

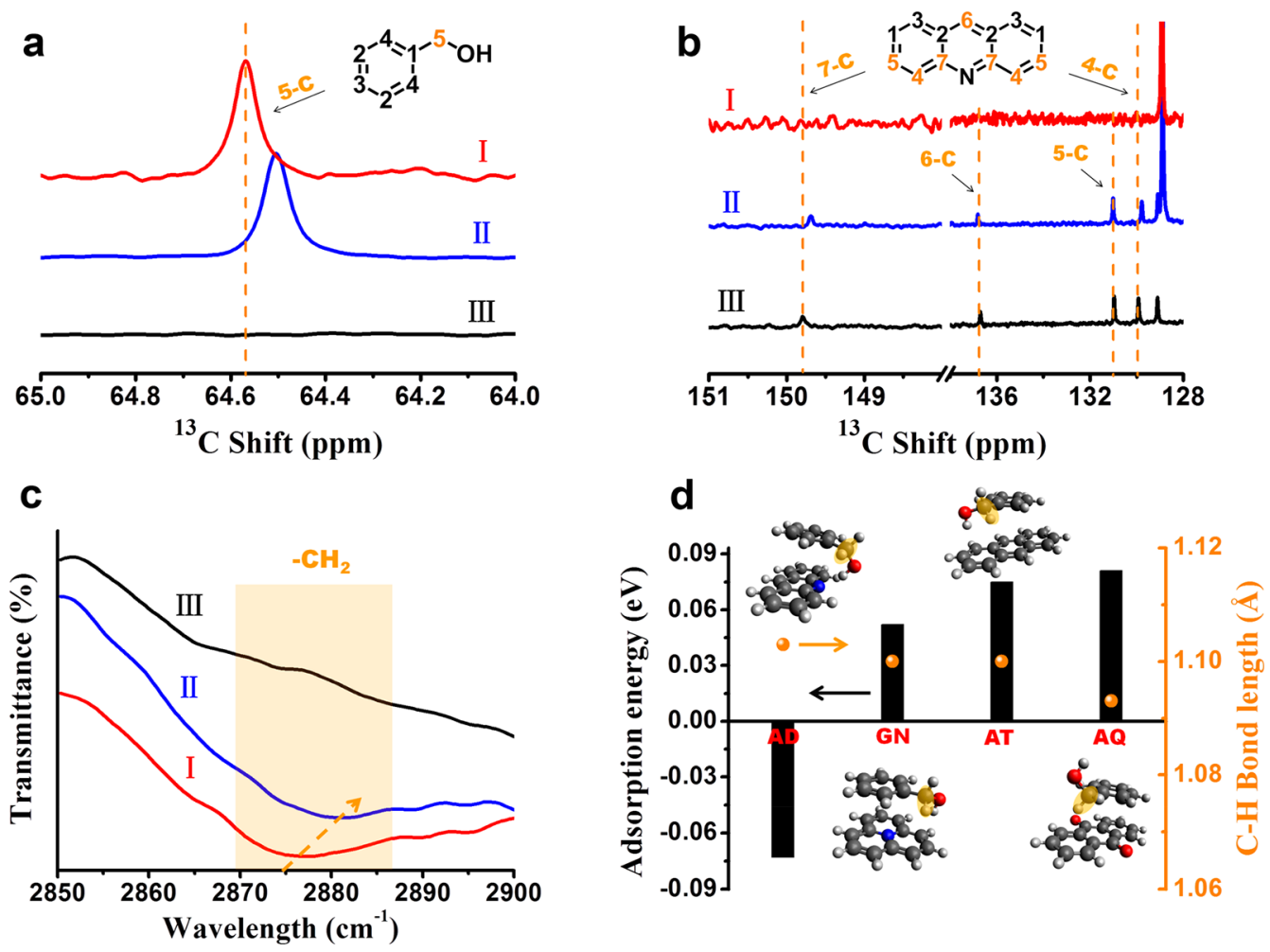

Figure 4. (a,b) In situ ${ }^{13} \mathrm{C}$ NMR spectra of I, II, and III systems at different shift regions. Here, I, II, and III systems represent $\mathrm{ACN}+\mathrm{Ph}$ $\mathrm{CH}_{2} \mathrm{OH}, \mathrm{ACN}+\mathrm{Ph}-\mathrm{CH}_{2} \mathrm{OH}+\mathrm{AD}$, and $\mathrm{ACN}+\mathrm{AD}$, respectively. (c) In situ ATR-IR spectra of I, II, and III systems. (d) Adsorption energy of $\mathrm{Ph}-\mathrm{CH}_{2} \mathrm{OH}$ molecule on $\mathrm{AD}, \mathrm{GN}$, and $\mathrm{AT}$ models with edge zigzag configuration and $\mathrm{AQ}$ with an edge $\mathrm{C}=\mathrm{O}$ group (the latter three use common theoretical model structures as a contrast) and the effect of different edge species on $\mathrm{C}-\mathrm{H}$ bond length of $-\mathrm{CH}_{2} \mathrm{OH}$. $\mathrm{Here}$, the $\mathrm{C}-$ $\mathrm{H}$ bond is marked by the yellow zone.

comparison to nanocarbons, aromatic organic molecules possess a similar carbon network structure with a conjugated $\pi$ system, ${ }^{17-21}$ whose electronic and reactive properties can be tuned by extending the benzene unit. They can provide variously designated $\mathrm{N}$ species (Scheme S1b). Thus, these kinds of molecules can be directly used as model catalysts to mimic the intrinsic edge structures of NDN catalysts and to identify the specific catalytically active components and the corresponding structure-activity relationship at a real molecular level.

As displayed in Figure $3 \mathrm{a}$ and Table S2, the catalytic activities of six organic molecules (carbazole (CB), phenanthridinone (PTD), acridine (AD), 9-phenanthrenamine (PTA), phenanthridine (PAD), and phenazine (PZ)) with designated $\mathrm{N}$ species as model catalysts are evaluated. Among these model catalysts with different $\mathrm{N}$ species (CB, PTD, PTA, and $\mathrm{AD}$ ), with $\mathrm{AD}$ having pyridinic $\mathrm{N}$ species, shows the highest turnover frequency (TOF) value $\left(0.157 \mathrm{~h}^{-1}\right)$. This indicates that pyridinic $\mathrm{N}$ may be an active component. We then investigated the $\pi$ conjugation structure of model catalysts to study the possible structure-function relationship of active components. As shown in Figure $3 \mathrm{~b}$, the TOF values of the model catalysts (quinoline $(\mathrm{QL}), \mathrm{AD}$, benz $[a]$ acridine $(\mathrm{BAD})$, dibenz $[a, i]$ acridine $(\mathrm{DBAD}-1))$ gradually increase with the number of their benzene units, indicating that the size of the $\pi$ conjugation structure is another positive factor for accelerating the activity. Moreover, we regulated the local environment and the distributed density of pyridinic $\mathrm{N}$ species to further investigate its structure-function by introducing another four model catalysts (PAD and PZ in Figure 3a, DBAD-2 and DBAD-3 in Figure $3 b)$. It can be found that $P A D$ with armchair-type pyridinic $\mathrm{N}$ species shows a similar TOF value compared to $\mathrm{AD}$ with zigzag-type pyridinic $\mathrm{N}$ species, suggesting that zigzag and armchair edge configurations are not critical when pyridinic $\mathrm{N}$ species are incorporated into the carbon network. This fact is also well supported by the similar TOF values of DBAD-1, DBAD-2, and DBAD-3. The function of intrinsic edge structure (heteroatom-free) of model catalysts is also studied by means of anthracene (AT) and phenanthrene (PT) with single zigzag or armchair edge structures. Compared with $\mathrm{AD}$ and $\mathrm{PAD}$, these two catalysts have lower TOF values of 0.09 and $0.051 \mathrm{~h}^{-1}$ (Figure S3), respectively, suggesting potentially positive role of edge structure. This result can be used to explain the origin of weak activity of BND, OLC, and CNT (Table 1). Additionally, the PZ catalyst with an increased density of $\mathrm{N}$ species carries a higher conversion rate $(11.9 \%$, Table S2) and a reasonable TOF feature in comparison to that of $\mathrm{AD}$ and PAD (Figure 3a), evidencing (1) the positive role of total $\mathrm{N}$ content in improving reactivity and (2) the independent contribution of each pyridinic $\mathrm{N}$ species to the reaction. The slightly lower TOF value of PZ (calculated per $\mathrm{N}$ atom) could be attributed to the steric effect between catalyst and substrate. As illustrated in Figure $3 \mathrm{c}, \mathrm{d}, \mathrm{AD}$ performs similar kinetic features, including the first-order process and obviously primary isotope effects in TBHP conditions, relative to the NBND bulk catalyst using $\mathrm{O}_{2}$ as oxidant, confirming that (1) using $\mathrm{AD}$ as model catalyst to investigate the nature of carbocatalysis is reasonable; (2) for NDN catalysts, the cleavage of $\alpha-\mathrm{H}$ of $-\mathrm{CH}_{2}$ is also the RDS toward the Ph$\mathrm{CH}_{2} \mathrm{OH}$ oxidation reaction in a TBHP atmosphere.

The detailed activation process of pyridinic $\mathrm{N}$ species for $\mathrm{Ph}$ $\mathrm{CH}_{2} \mathrm{OH}$ is further investigated by using in situ nuclear 
Scheme 2. Catalytic Oxidation of Substituted Alcohols to Corresponding Aldehydes over NBND Catalyst ${ }^{a}$

$$
\mathrm{R} \widehat{\mathrm{OH}} \stackrel{\mathrm{NBND}}{\stackrel{\mathrm{Oxidant} \text { or } \mathrm{O}_{2} \Delta}{\mathrm{R}}} \mathrm{R} \mathrm{O}
$$

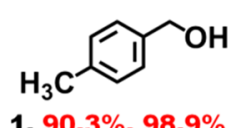

1. $90.3 \%, 98.9 \%$ $12 \mathrm{~h}$, [a]

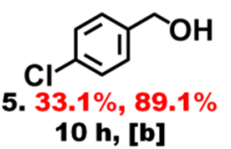

5. $90.2 \%, 85.3 \%$,

$48 \mathrm{~h},[\mathrm{i}]$

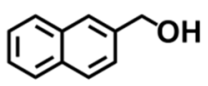

9. $41.1 \%, 98.9 \%$ 8 h, [b]<smiles>COc1ccc(CO)cc1OC</smiles>

13. $34.9 \%, 88.2 \%$ $16 \mathrm{~h}$, [d]

13. $52.5 \%$, $97.8 \%$, $36 \mathrm{~h}$, [i]<smiles>COc1ccc(CO)c(OC)c1OC</smiles>

17. $31.2 \%, 86.7 \%$ 20 h, [d]

17. $64.2 \%, 90.7 \%$, $48 \mathrm{~h},[i]$

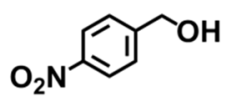

2. $39.5 \%, 93.9 \%$

$6 \mathrm{~h}$, [b]<smiles>OCc1cccnc1</smiles>

6. $32.7 \%, 88.9 \%$ $12 \mathrm{~h}$, [b]

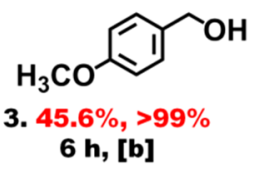<smiles>OC/C=C/c1ccccc1</smiles>

7. $78.2 \%, 82.9 \%$

24 h, [b]

7. $100 \%, 60 \%, 24$ h, [e]

7. $80 \%, 79 \%, 120$ h, [f]

7. $83.2 \%, 81.3 \%, 28$ h, [i]

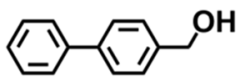

10. $32.4 \%, 95.2 \%$

$$
8 \mathrm{~h}, \text { [b] }
$$<smiles>COc1ccc(CO)cc1F</smiles>

14. $33.4 \%, 86.7 \%$

24 h, [c]

14. $60.2 \%, 98.0 \%$,

$40 \mathrm{~h}$, [i]

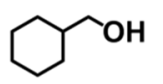

18. $33.2 \%, 80.2 \%$

$12 \mathrm{~h}$, [d]

18. $72.5 \%, 94.3 \%$,

36 h, [i]

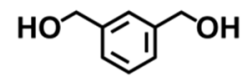

11. $33.7 \%, 88.9 \%$ 12 h, [c]

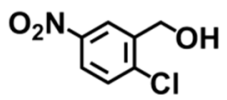

15. $32.8 \%$, $90.5 \%$ $20 \mathrm{~h}$, [c]

15. $57.2 \%, 98.8 \%$, $40 \mathrm{~h},[\mathrm{i}]$

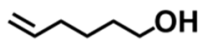

19. $37.8 \%, 78.9 \%$ $20 \mathrm{~h}$, [d]

19. $34.2 \%, 62.1 \%$, [g]

19. $68.2 \%, 84.7 \%, 48$ h, [i] 20. $77.9 \%, 86.3 \%, 48$ h, [i]

${ }^{a}$ Reaction conditions: [a] $10 \mathrm{mg}$ of catalyst, $2.0 \mathrm{mmol}$ substrate, $2.0 \mathrm{mmol} \mathrm{TBHP}$, solvent-free, $70{ }^{\circ} \mathrm{C}$; [b] $5 \mathrm{~mL}$ of ACN as solvent; [c] $5 \mathrm{~mL}$ of ACN, 1.0 mmol substrate; [d] $1.0 \mathrm{mmol}$ substrate; [e] ref 22, $n$ (substrate $) /($ cat $)=50, n(\mathrm{TBHP}) /($ substrate $)=2$, $\left[\mathrm{Fe}(\text { bipy })_{3}\right](\mathrm{OTf})_{2}$ catalyst, 25 ${ }^{\circ} \mathrm{C}$; [f] ref 23, $1.0 \mathrm{mmol}$ substrate, $20 \mathrm{mg}$ of $\mathrm{Co}-\mathrm{N}-\mathrm{C}$ catalyst, $5 \mathrm{~mL}$ of ethanol, $0.1 \mathrm{MPa} \mathrm{O}_{2}, 80{ }^{\circ} \mathrm{C}$; [g,h] conditions are the same as stated in footnote a, except the catalysts used are $5 \mathrm{wt} \% \mathrm{Pt} / \mathrm{C}$ and $5 \mathrm{wt} \% \mathrm{Ru} / \mathrm{C}$; [i] $0.1 \mathrm{MPa} \mathrm{O}_{2}, 120^{\circ} \mathrm{C}, 10 \mathrm{~mL}$ of $\mathrm{ACN}$.

magnetic resonance (NMR) and in situ attenuated total reflectance infrared (ATR-IR) measurements. As shown in Figure $4 \mathrm{a}$, the presence of an $\mathrm{AD}$ catalyst leads to a significant ${ }^{13} \mathrm{C}$ chemical shift of the $-\mathrm{CH}$ bond $(5-\mathrm{C})$ of the $-\mathrm{CH}_{2} \mathrm{OH}$ group, suggesting that $\mathrm{AD}$ is capable of activating the $\mathrm{C}-\mathrm{H}$ bond. Moreover, neighboring carbon atoms (7-C) of pyridinic $\mathrm{N}$ species on $\mathrm{AD}$ are demonstrated to be the most possible active sites because of the most obvious ${ }^{13} \mathrm{C}$ chemical shift compared with other carbon atoms of $\mathrm{AD}$ at different positions (e.g., 4-C, 5-C, or 6-C), as illustrated in Figure 4b. Due to their strong interaction, the chemical shift of ${ }^{13} \mathrm{C}$ NMR in both $\mathrm{AD}$ and alcohol molecules may be associated with the generation of a new transition state (or intermediate species), during which the occurrence of electron transfer helps to shield the ${ }^{13} \mathrm{C}$ site. With the help of ATR-IR spectra, the blue shift $(\sim 7$ $\mathrm{cm}^{-1}$ ) of $-\mathrm{CH}_{2}$ and of the $-\mathrm{CH}_{2} \mathrm{OH}$ group at $2882 \mathrm{~cm}^{-1}$ in the presence of $\mathrm{AD}$ catalyst is observed (Figure $4 \mathrm{c}$ and Figure S4), further suggesting that the introduction of $\mathrm{AD}$ could activate the $\mathrm{C}-\mathrm{H}$ bond by stretching the bond length. The results of density functional theory (DFT) calculations (Figure
$4 \mathrm{~d}$ ) indicate that $\mathrm{AD}$ shows the most negative adsorption energy $(-0.073 \mathrm{eV})$ compared to that of GN (graphitic N), AT (a model structure with edge zigzag configuration), and AQ (a model structure with edge $\mathrm{C}=\mathrm{O}$ species). Additionally, $\mathrm{AD}$ could maximally lengthen the $\mathrm{C}-\mathrm{H}$ bond of $\mathrm{CH}_{2}$ from $1.093 \AA$ of the ground state to $1.112 \AA$ by an adsorption effect. Thus, we can conclude that $\mathrm{AD}$ having pyridinic $\mathrm{N}$ is the easiest one to adsorb a $\mathrm{Ph}-\mathrm{CH}_{2} \mathrm{OH}$ molecule, and it shows the most positive behavior among the four structures to activate the $\mathrm{C}-\mathrm{H}$ bond in the RDS. This is in good accordance with the results of NMR and ATR-IR experiments.

Feasibilities for Other Substituted Alcohol and Phenol Oxidation Reactions. Recently, the production of aldehydes from alcohols was carried out by means of carbocatalysts and metal-based catalysts. It should be mentioned that, among these catalysts, especially for carbocatalysts, they are only capable of achieving selective oxidation of alcohols with easily oxidizable functionalities. Herein, the substrate scope was examined to explore the feasibility of a catalyst with enriched pyridinic $\mathrm{N}$ species for the 
Scheme 3. Catalytic Oxidation of Substituted Phenols to Corresponding $p$-Benzoquinones over NBND Catalyst ${ }^{a}$

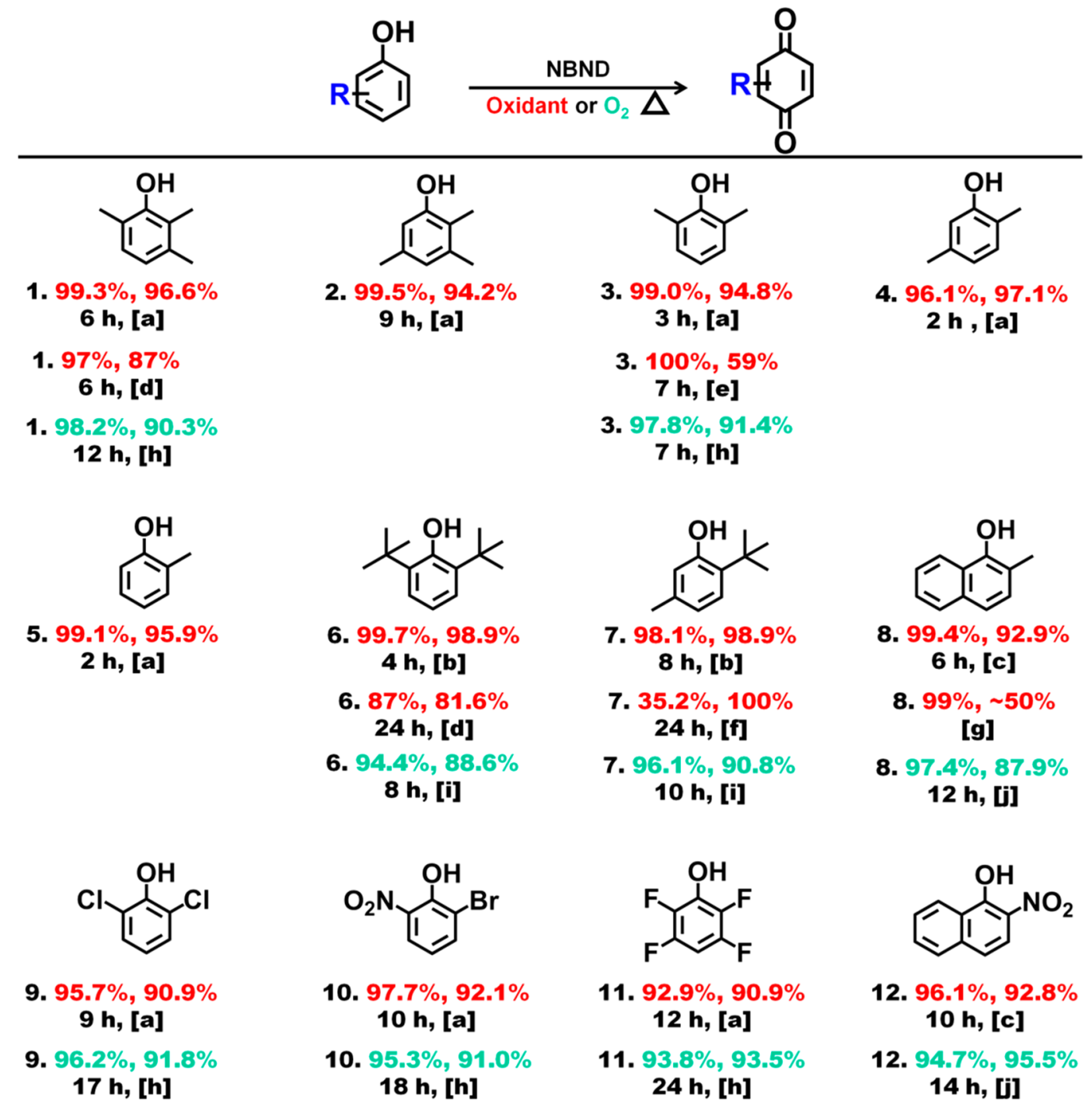

${ }^{a}$ Reaction conditions: [a] $8 \mathrm{mg}$ of catalyst, $1.0 \mathrm{mmol}$ substrate, $4.0 \mathrm{mmol} 35 \% \mathrm{H}_{2} \mathrm{O}_{2}, 5 \mathrm{~mL}$ of ACN, $60{ }^{\circ} \mathrm{C}$; [b] $50{ }^{\circ} \mathrm{C}$; [c] $0.05 \mathrm{mmol}$ substrate, 60 ${ }^{\circ} \mathrm{C}$; [d] ref 33, $200 \mathrm{mg}$ of Ti-HMS catalyst, $n\left(\mathrm{H}_{2} \mathrm{O}_{2}\right) / n(\mathrm{phenol})=1, \mathrm{MeOH}$ solvent, $60{ }^{\circ} \mathrm{C}$; [e] ref 34, $1 \mathrm{mmol}$ substrate, $5 \mathrm{~mL}$ of acetone, 0.02 mmol Cs $3 \mathrm{H} 1 \mathrm{M} 11 \mathrm{PV} 1$ catalyst, $22 \mathrm{mmol} \mathrm{H}_{2} \mathrm{O}_{2}, 20^{\circ} \mathrm{C}$; [f] ref 35, $150 \mathrm{mg}$ of Sm-based catalyst, $10 \mathrm{mmol}$ substrate, $34.9 \mathrm{mmol} \mathrm{H}_{2} \mathrm{O}_{2}, \mathrm{ACN}^{\circ}$ solvent, $60{ }^{\circ} \mathrm{C}$; $[\mathrm{g}] \mathrm{CrO}_{3} / \mathrm{CH}_{3} \mathrm{COOH} / \mathrm{H}_{2} \mathrm{SO}_{4}$ homogeneous industrial catalyst, $60-90{ }^{\circ} \mathrm{C}$; $[\mathrm{h}] 0.1 \mathrm{MPa} \mathrm{O}_{2}, 110{ }^{\circ} \mathrm{C}, 10 \mathrm{~mL}$ of $\mathrm{ACN}$; [i] $0.1 \mathrm{MPa} \mathrm{O}_{2}, 100$ ${ }^{\circ} \mathrm{C}, 10 \mathrm{~mL}$ of $\mathrm{ACN}$; [j] $0.05 \mathrm{mmol}$ substrate, $0.1 \mathrm{MPa}_{2}, 110{ }^{\circ} \mathrm{C}, 10 \mathrm{~mL}$ of ACN.

oxidation of complicated alcohols. In Scheme 2, the results show that the NBND catalyst was effective for alcohols with substituted, heterocyclic, aliphatic, and unsaturated structures under both TBHP and $\mathrm{O}_{2}$ conditions, even in solvent-free conditions. The selective oxidation of para-substituted and unsaturated alcohols provided the substrate conversion of 20.2-90.3\% together with excellent selectivity (>82.9\%) toward the desired products (Scheme 2, 1-5, 7, 8, and 10). It is worthy to note that the conversion of cinnamic alcohol and the selectivity for cinnamyl aldehyde are comparable to those of the reported transition-metal catalysts (Scheme 2, 7). ${ }^{22,23}$ Additionally, NBND has the ability to carry out the oxidation of di- and trisubstituted alcohols $(12-17)$, even for heterocycle-substituted alcohols $(6,18)$ under solvent or solvent-free conditions. The conversion of the alcohols and the selectivity for the corresponding aldehydes reached 31.2$34.7 \%$ and $80.2-98.1 \%$, respectively. The oxidation of aliphatic alcohols (19 and 20) could achieve comparable selectivity to 5 wt \% Pt/C and 5 wt \% Ru/C under solvent-free conditions. It should be emphasized that, at an aerobic atmosphere, NBND also exhibited impressive activity for some substituted, unsaturated, and aliphatic alcohols (Scheme 2, 5, 7, 8, and 13-20).

Selective oxidation of phenols has been considered to be a key step in the biosynthesis of natural product classes (e.g., quinones) inspired by the ground-breaking work of Barton and Erdtman. ${ }^{24-26}$ For example, thymoquinone is a highly active antitumor. 2,3,5-Trimethyl-1,4-benzoquinone (TMBQ) and 2methyl-1,4-naphthoquinone (MNQ) are key intermediates to synthesize vitamin $\mathrm{E}$ and vitamin $\mathrm{K} 3$, respectively. ${ }^{27-29}$ Recently, selective preparation of $p$-benzoquinones from the substituted phenols based on $\mathrm{Cu}$ or $\mathrm{Cr}$ catalysts was still inefficient because of the rather favorable $\mathrm{C}-\mathrm{O}$ and $\mathrm{C}-\mathrm{C}$ coupling reactions caused by phenoxy and benzylic radicals. ${ }^{30,31}$ Some alternative routes were dedicated to developing a homogeneous catalytic system (and/or strong acidic/ 
corrosion conditions) to improve the yields of desired products. $^{29,32}$ In the present work, NBND shows excellent conversion and selectivity outputs for the synthesis of natural product $p$-benzoquinones in the presence of $\mathrm{H}_{2} \mathrm{O}_{2}$ or $\mathrm{O}_{2}$ (Scheme 3). For example, TMBQ and thymoquinone (vitamin $\mathrm{E}$ intermediates and antibacterial agent, respectively) were produced efficiently from 2,3,6-trimethylphenol and thymol, respectively, along with impressive activities (1 and 7). The oxidation for other substituted phenols resulted in $87.9-98.9 \%$ selectivity of corresponding $p$-benzoquinones (3-12). Compared with the reported metal-based catalysts and the industrial homogeneous catalysts, NBND showed good catalytic performance at similar reaction conditions $(3,6-8)$, especially for synthesizing the vitamin $\mathrm{K} 3$ intermediate MNQ (8)..$^{33-35}$ Thus, a cost-effective heterogeneous metal-free catalytic system to effectively realize the high outputs of complicated aldehydes and natural product quinones has been achieved by NBND with enriched pyridinic $\mathrm{N}$ species.

\section{CONCLUSION}

In summary, we have reported a simple and effective approach to prepare $\mathrm{N}$-doped nanocarbon materials with enriched pyridinic N configuration. Such NDN catalysts (including nitrogen-doped bucky nanodiamond, nitrogen-doped CNTs, nitrogen-doped oxidized bucky nanodiamond, and nitrogendoped onion-like carbon) are demonstrated to perform impressive reactivity for catalytic oxidation of alcohols (21 examples). The possible role of each typical $\mathrm{N}$ species has been studied in alcohol oxidation reactions by using aromatic model catalysts. Pyridinic N species play an unexpected role, which differ from the conventional active sites (graphitic nitrogen) only indicated for this aerobic reaction and thus broaden the concept of active sites in other oxidation reactions, such as phenol oxidation (12 examples). The structure-function relationship of the active components can be established by delicately controlling their longitudinal extension $(\pi$-conjugated structures), local environment, and distribution density. Pyridinic N groups located at zigzag and armchair edge configurations show similar catalytic performance, and each pyridinic $\mathrm{N}$ is demonstrated experimentally to contribute independently to the probe reaction. The activation process of the $\alpha-\mathrm{H}$ of $-\mathrm{CH}_{2} \mathrm{OH}$ over both bulk and model catalysts is clarified to be a rate-determining step of the catalytic reaction using kinetic isotope effects. Furthermore, neighboring carbon atoms of pyridinic $\mathrm{N}$ species are confirmed to be possible active sites, which could substantially facilitate the RDS process.

\section{EXPERIMENTAL SECTION}

Materials. Benzyl alcohol, quinoline (QL), acridine ( $\mathrm{AD})$, tertbutyl hydroperoxide (TBHP, $\sim 65 \mathrm{wt} \%$ in water), acetonitrile (ACN), and 2,3,5-trimethylphenol were purchased from Alfa. Carbazole (CB), phenanthridinone (PTD), anthracene (AT), phenanthrene (PT), 2,3,6-trimethylphenol, 2,5-dimethylbenzoquinone, 2,6-di-tert-butylphenol, and 2-methyl-1,4-naphthoquinone (MNQ) were supplied by TCI. 9-Phenanthrenamine (PTA), phenazine (PZ), phenanthridine (PAD), benz $[a]$ acridine (BAD), dibenz $[a, c]$ acridine (DBAD-2), dibenz $[a, i]$ acridine (DBAD-1), dibenz $[a, h]$ acridine (DBAD-3), 2,6dimethylphenol, 2,6-dimethylbenzoquinone, 2,5-dimethylphenol, 2,6di-tert-butyl-p-benzoquinone, 2-methyl-1-naphthol, 2-methylphenol, methyl-p-benzoquinone, 2,6-dichlorophenol, 2,3,5,6-tetrafluorophenol, 2-nitro-1-naphthol, 2-bromo-6-nitrophenol, tetrafluoro-1,4-benzoquinone, 2-nitro-1,4-naphthoquinone, 2,6-dichloro-1,4-benzoquinone, and all of the aldehydes were obtained from Sigma-Aldrich.
Acetonitrile was purchased from Sinopharm Chemical Reagent Co., Ltd. All reagents were used without further purification. Purified ultradispersed nanodiamond was bought from Beijing Grish Hitech Co. (China), produced by detonation, and purified by acid washing. Its average particle size is $\sim 5 \mathrm{~nm}$. The noncombustible contaminations were tested by an inductively coupled plasma optical emission spectrometer, and the impurities are $\mathrm{Fe}<50 \mathrm{ppm}, \mathrm{Cr}<10 \mathrm{ppm}, \mathrm{Al}<$ 50 ppm, $\mathrm{Cu}<10$ ppm, $\mathrm{Mg}<10 \mathrm{ppm}, \mathrm{Ti}<10 \mathrm{ppm}$, and $\mathrm{Ca}<50 \mathrm{ppm}$. Carbon nanotubes (CNTs) were bought from Shandong DazhanTechnology Ltd. and were further treated with water-diluted $\mathrm{HCl}$ (volume ratio is $1: 1$ ) before use.

Sample Preparation. Preparation of BND and OLC. Bucky nanodiamond is a sp ${ }^{2} / \mathrm{sp}^{3}$ hybrid material consisting of a $\mathrm{sp}^{3}$ carbon core covered by a few $\mathrm{sp}^{2}$ graphite-like layers. In the present work, BND with a graphite-like shell structure was produced by annealing purified ND at $1300{ }^{\circ} \mathrm{C}$ for $4 \mathrm{~h}$ in an argon atmosphere. Similarly, OLC with multiple layers of curved $\mathrm{sp}^{2}$ carbon concentric shells can be obtained by annealing ND at $1500{ }^{\circ} \mathrm{C}$ for $30 \mathrm{~min}$ in an argon atmosphere. The morphology of BND, CNTs, and OLC can be found in Figure S1. The surface area of BND and OLC is 386 and $463 \mathrm{~m}^{2} / \mathrm{g}$, respectively. ${ }^{36}$ The surface area of CNTs is about $230 \mathrm{~m}^{2} / \mathrm{g}$.

Preparation of NBND, NOBND, NCNTs, and NOLC. NBND, NCNTs, and NOLC were prepared using a CVD-like method. Briefly, $0.2 \mathrm{~g}$ of as-prepared BND, CNTs, and OLC samples was evenly spread in the tube furnace and annealed at $350{ }^{\circ} \mathrm{C}$ (at a heating rate of $5 \mathrm{~K} / \mathrm{min}$ ) for $2 \mathrm{~h}$ under ammonia gas $(50 \mathrm{~mL} / \mathrm{min})$. Then, the pyrimidine vapor was further transported into the tube furnace by virtue of ammonia gas and maintained at $350{ }^{\circ} \mathrm{C}$ for another $2 \mathrm{~h}$. Afterward, the furnace was cooled naturally to room temperature. The final products were noted as NBND, NCNTs, and NOLC.

NOBND was prepared by using the reported method. ${ }^{37}$ Briefly, BND that was obtained from $1300{ }^{\circ} \mathrm{C}$ treatment was added to 100 $\mathrm{mL}$ of concentrated nitric acid under continuous stirring at $120^{\circ} \mathrm{C}$ for $4 \mathrm{~h}$. The product was filtered, washed with deionized water and ethanol, and then dried at $60{ }^{\circ} \mathrm{C}$ for several hours. The product was then annealed at $450{ }^{\circ} \mathrm{C}$ under an ammonia atmosphere for $8 \mathrm{~h}$. The preparation method of NBND-1 was the same as that of NBND except that the annealing temperature was $250{ }^{\circ} \mathrm{C}$.

Characterization. X-ray photoelectron spectroscopy was performed on an ESCALAB 250 XPS system with a monochromatized Al $\mathrm{K} \alpha$ X-ray source. The Brunauer-Emmett-Teller (BET) specific surface area measurement was conducted on a Micromeritics ASAP2020 analyzer. Fourier transform infrared spectra with an attenuated total reflectance model were collected at a resolution of 4 $\mathrm{cm}^{-1}$ on a Nicolet iS50 instrument at the reaction temperature of 70 ${ }^{\circ} \mathrm{C} .{ }^{13} \mathrm{C}$ NMR spectra were acquired on a $600 \mathrm{MHz}$ Bruker Avance III $\mathrm{HD}$ spectrometer at $50{ }^{\circ} \mathrm{C}$. The ${ }^{13} \mathrm{C}$ NMR spectra were measured with waltz16 pulse-gated ${ }^{1} \mathrm{H}$ decoupling. The ${ }^{13} \mathrm{C}$ shifts were externally referenced to DMSO at $39.5 \mathrm{ppm}$. Adsorption energy is operated by DFT using a TPSS functional, dispersion corrections, and def2-TZVP basis sets. ${ }^{38-43}$

The oxidation reactions of alcohols and phenols were operated in a $48 \mathrm{~mL}$ pressure bottle containing certain amounts of catalyst, substrates, and oxidants $\left(\mathrm{H}_{2} \mathrm{O}_{2}\right.$ or TBHP $)$. When $\mathrm{O}_{2}$ was used as an oxidant, the experiments were performed in $25 \mathrm{~mL}$ round-bottom flasks. The flask was vacuumed and purged with oxygen (99.9\%) three times before it was finally connected with an oxygen balloon. A given amount of ethylbenzene was added as an internal standard in the reaction solution after reaction for product analysis. The reaction solution was sampled periodically and analyzed using gas chromatography with a HP-5 column (Agilent 7890A). Conversion, yield, and selectivity for the oxidation of alcohols to target products were defined as follows:

$$
\begin{aligned}
& \text { conversion }(\%)=\left[\left(C_{0}-C_{\mathrm{r}}\right) / C_{0}\right] \times 100 \\
& \text { selectivity }(\%)=\left[C_{\mathrm{p}} /\left(C_{0}-C_{\mathrm{r}}\right)\right] \times 100 \\
& \text { yield }(\%)=\text { conversion }(\%) \times \text { selectivity }(\%)
\end{aligned}
$$


where $C_{0}$ is the initial concentration of alcohol and $C_{\mathrm{r}}$ and $C_{\mathrm{p}}$ are the concentration of reactants and products, respectively, at a certain time after the reaction. The concentration of reactants and products can be measured by an internal standard method (based on an integral area method).

TOF values were calculated by using the following equation:

$$
\begin{gathered}
\text { TOF }=\frac{\text { the number of product molecules }}{\text { the number of } \mathrm{N} \text { atoms in molecular catalysts } \times t} \\
=\frac{n_{0} \times\left(\text { yield }_{\text {product }}-\text { yield }_{\text {blank }}\right) \times N_{\mathrm{A}}}{n_{\text {active site }} \times N_{\mathrm{A}} \times t}
\end{gathered}
$$

Here, $n_{0}$ is the initial molar of alcohol and $n_{\text {active sites }}$ is the moles of corresponding groups (e.g., pyridinic N species). $N_{\mathrm{A}}$ is Avogadro's constant $\left(6.02 \times 10^{23}\right)$, and $t$ represents reaction time. In the present work, each pyridinic $\mathrm{N}$ atom in a $\mathrm{PZ}$ model catalyst is calculated separately.

\section{ASSOCIATED CONTENT}

\section{(S Supporting Information}

The Supporting Information is available free of charge at https://pubs.acs.org/doi/10.1021/acsnano.9b05856.

Additional figures and tables for XPS spectra, IR spectra, BET analysis, and activity evaluation of various bulk catalysts and model catalysts (PDF)

\section{AUTHOR INFORMATION}

\section{Corresponding Authors}

*E-mail: yang-ming.lin@cec.mpg.de.

*E-mail: linhui.yu@cec.mpg.de.

\section{ORCID}

Yangming Lin: 0000-0002-3547-9133

Bingsen Zhang: 0000-0002-2607-2999

Gabriele Centi: 0000-0001-5626-9840

Saskia Heumann: 0000-0003-3594-6392

\section{Notes}

The authors declare no competing financial interest.

\section{ACKNOWLEDGMENTS}

We thank Youyi Lin for his emotional support. We also acknowledge the financial support from the "Strategic Priority Research Program" of the Chinese Academy of Sciences (Grant No. XDA09030103) and National Natural Science Foundation of China (Grant No. 91545119). The Max Planck Society is acknowledged for funding. Unfortunately, Prof. Dang Sheng Su passed away a few days before submission, but he made a great contribution to the present work.

\section{REFERENCES}

(1) Davis, S. E.; Ide, M. S.; Davis, R. J. Selective Oxidation of Alcohols and Aldehydes over Supported Metal Nanoparticles. Green Chem. 2013, 15, 17-45.

(2) ten Brink, G.-J.; Arends, I. W. C. E.; Sheldon, R. A. Green, Catalytic Oxidation of Alcohols in Water. Science 2000, 287, 16361639.

(3) Long, J.; Xie, X.; Xu, J.; Gu, Q.; Chen, L.; Wang, X. NitrogenDoped Graphene Nanosheets as Metal-Free Catalysts for Aerobic Selective Oxidation of Benzylic Alcohols. ACS Catal. 2012, 2, 622631.

(4) Patel, M. A.; Luo, F.; Khoshi, M. R.; Rabie, E.; Zhang, Q.; Flach, C. R.; Mendelsohn, R.; Garfunkel, E.; Szostak, M.; He, H. P-Doped Porous Carbon as Metal Free Catalysts for Selective Aerobic Oxidation with an Unexpected Mechanism. ACS Nano 2016, 10, 2305-2315.
(5) Lin, Y.; Su, D. Fabrication of Nitrogen-Modified Annealed Nanodiamond with Improved Catalytic Activity. ACS Nano 2014, 8, $7823-7833$.

(6) Xue, L.; Li, Y.; Liu, X.; Liu, Q.; Shang, J.; Duan, H.; Dai, L.; Shui, J. Zigzag Carbon as Efficient and Stable Oxygen Reduction Electrocatalyst for Proton Exchange Membrane Fuel Cells. Nat. Commun. 2018, 9, 3819.

(7) Lin, Y.; Wu, S.; Shi, W.; Zhang, B.; Wang, J.; Kim, Y. A.; Endo, M.; Su, D. S. Efficient and Highly Selective Boron-Doped Carbon Materials-Catalyzed Reduction of Nitroarenes. Chem. Commun. 2015, 51, 13086-13089.

(8) Lin, Y.; Wu, K.-H.; Lu, Q.; Gu, Q.; Zhang, L.; Zhang, B.; Su, D.; Plodinec, M.; Schlögl, R.; Heumann, S. Electrocatalytic Water Oxidation at Quinone-on-Carbon: A Model System Study. J. Am. Chem. Soc. 2018, 140, 14717-14724.

(9) Gao, Y.; Hu, G.; Zhong, J.; Shi, Z.; Zhu, Y.; Su, D. S.; Wang, J.; Bao, X.; Ma, D. Nitrogen-Doped $\mathrm{sp}^{2}$-Hybridized Carbon as a Superior Catalyst for Selective Oxidation. Angew. Chem., Int. Ed. 2013, 52, 2109-2113.

(10) Guo, D.; Shibuya, R.; Akiba, C.; Saji, S.; Kondo, T.; Nakamura, J. Active Sites of Nitrogen-Doped Carbon Materials for Oxygen Reduction Reaction Clarified Using Model Catalysts. Science 2016, $351,361-365$.

(11) Watanabe, H.; Asano, S.; Fujita, S.; Yoshida, H.; Arai, M. Nitrogen-Doped, Metal-Free Activated Carbon Catalysts for Aerobic Oxidation of Alcohols. ACS Catal. 2015, 5, 2886-2894.

(12) Ndolomingo, M. J.; Meijboom, R. Selective Liquid Phase Oxidation of Benzyl Alcohol to Benzaldehyde by tert-Butyl Hydroperoxide over $\gamma-\mathrm{Al}_{2} \mathrm{O}_{3}$ Supported Copper and Gold Nanoparticles. Appl. Surf. Sci. 2017, 398, 19-32.

(13) Mahdavi, V.; Hasheminasab, H. R. Vanadium Phosphorus Oxide Catalyst Promoted by Cobalt Doping for Mild Oxidation of Benzyl Alcohol to Benzaldehyde in the Liquid Phase. Appl. Catal., A 2014, 482, 189-197.

(14) Gómez-Gallego, M.; Sierra, M. A. Kinetic Isotope Effects in the Study of Organometallic Reaction Mechanisms. Chem. Rev. 2011, $111,4857-4963$.

(15) Tsunoyama, H.; Sakurai, H.; Negishi, Y.; Tsukuda, T. SizeSpecific Catalytic Activity of Polymer-Stabilized Gold Nanoclusters for Aerobic Alcohol Oxidation in Water. J. Am. Chem. Soc. 2005, 127, 9374-9375.

(16) Makwana, V. D.; Son, Y. C.; Howell, A. R.; Suib, S. L. The Role of Lattice Oxygen in Selective Benzyl Alcohol Oxidation Using OMS2 Catalyst: A Kinetic and Isotope-Labeling Study. J. Catal. 2002, 210, $46-52$.

(17) Wu, H.; Su, C.; Tandiana, R.; Liu, C.; Qiu, C.; Bao, Y.; Wu, J.; Xu, Y.; Lu, J.; Fan, D.; Loh, K. P. Graphene-Oxide-Catalyzed Direct $\mathrm{CH}-\mathrm{CH}$-Type Cross-Coupling: The Intrinsic Catalytic Activities of Zigzag Edges. Angew. Chem., Int. Ed. 2018, 57, 10848-10853.

(18) Narita, A.; Wang, X.-Y.; Feng, X.; Müllen, K. New Advances in Nanographene Chemistry. Chem. Soc. Rev. 2015, 44, 6616-6643.

(19) Chen, L.; Hernandez, Y.; Feng, X.; Müllen, K. From Nanographene and Graphene Nanoribbons to Graphene Sheets: Chemical Synthesis. Angew. Chem., Int. Ed. 2012, 51, 7640-7654.

(20) Rieger, R.; Müllen, K. Forever Young: Polycyclic Aromatic Hydrocarbons as Model Cases for Structural and Optical Studies. J. Phys. Org. Chem. 2010, 23, 315-325.

(21) Berger, R.; Giannakopoulos, A.; Ravat, P.; Wagner, M.; Beljonne, D.; Feng, X.; Müllen, K. Synthesis of Nitrogen-Doped ZigZag-Edge Peripheries: Dibenzo-9a-azaphenalene as Repeating Unit. Angew. Chem., Int. Ed. 2014, 53, 10520-10524.

(22) Chàvez, J. E.; Crotti, C.; Zangrando, E.; Farnetti, E. Iron Complexes with Nitrogen Bidentate Ligands as Green Catalysts for Alcohol Oxidation. J. Mol. Catal. A: Chem. 2016, 421, 189-195.

(23) Slot, T. K.; Eisenberg, D.; van Noordenne, D.; Jungbacker, P.; Rothenberg, G. Cooperative Catalysis for Selective Alcohol Oxidation with Molecular Oxygen. Chem. - Eur. J. 2016, 22, 12307-12311. 
(24) Bozell, J. J.; Hames, B. R.; Dimmel, D. R. Cobalt-Schiff Base Complex Catalyzed Oxidation of Para-Substituted Phenolics. Preparation of Benzoquinones. J. Org. Chem. 1995, 60, 2398-2404.

(25) Barton, D. H. R.; Cohen, T. Festschrift Prof. Dr. Arthur Stoll zum Siebzigsten Geburstag; Birkhauser: Basel, 1957; p 117.

(26) Erdtman, H.; Wachtmeister, C. A. Festschrift Prof. Dr. Arthur Stoll zum Siebzigsten Geburstag; Birkhauser: Basel, 1957; p 144.

(27) Worthen, D. R.; Ghosheh, O. A.; Crooks, P. A. The In Vitro Anti-Tumor Activity of Some Crude and Purified Components of Blackseed, Nigella Sativa L. Anticancer Res. 1998, 18, 1527-1532.

(28) Sun, H.; Harms, K.; Sundermeyer, J. Aerobic Oxidation of 2, 3, 6-Trimethylphenol to Trimethyl-1, 4-Benzoquinone with Copper (II) Chloride as Catalyst in Ionic Liquid and Structure of the Active Species. J. Am. Chem. Soc. 2004, 126, 9550-9551.

(29) Bohle, A.; Schubert, A.; Sun, Y.; Thiel, W. R. A New Metal-Free Access to Vitamin K3. Adv. Synth. Catal. 2006, 348, 1011-1015.

(30) Lee, Y. E.; Cao, T.; Torruellas, C.; Kozlowski, M. C. Selective Oxidative Homo-and Cross-Coupling of Phenols with Aerobic Catalysts. J. Am. Chem. Soc. 2014, 136, 6782-6785.

(31) Esguerra, K. V. N.; Fall, Y.; Lumb, J.-P. A Biomimetic Catalytic Aerobic Functionalization of Phenols. Angew. Chem., Int. Ed. 2014, 53, $5877-5881$.

(32) Molander, G. A.; Knochel, P. Comprehensive Organic Synthesis, 2nd ed.; Elsevier: Oxford, 2014; Vol. 3, pp 56-740.

(33) Cheneviere, Y.; Caps, V.; Tuel, A. Gold-Catalyzed Oxidation of Substituted Phenols by Hydrogen Peroxide. Appl. Catal., A 2010, 387, 129-134.

(34) Villabrille, P.; Romanelli, G.; Vazquez, P.; Cáceres, C. Vanadium-Substituted Keggin Heteropolycompounds as Catalysts for Ecofriendly Liquid Phase Oxidation of 2, 6-Dimethylphenol to 2, 6-Dimethyl-1, 4-Benzoquinone. Appl. Catal., A 2004, 270, 101-111.

(35) Ay, B.; Yildiz, E.; Felts, A. C.; Abboud, K. A. Hydrothermal Synthesis, Structure, Heterogeneous Catalytic Activity and Photoluminescent Properties of a Novel Homoleptic Sm (III)-Organic Framework. J. Solid State Chem. 2016, 244, 61-68.

(36) Lin, Y.; Feng, Z.; Yu, L.; Gu, Q.; Wu, S.; Su, D. S. Insights into the Surface Chemistry and Electronic Properties of $\mathrm{sp}^{2}$ and $\mathrm{sp}^{3}$ Hybridized Nanocarbon Materials for Catalysis. Chem. Commun. 2017, 53, 4834-4837.

(37) Lin, Y.; Pan, X.; Qi, W.; Zhang, B.; Su, D. S. Nitrogen-Doped Onion-Like Carbon: A Novel and Efficient Metal-Free Catalyst for Epoxidation Reaction. J. Mater. Chem. A 2014, 2, 12475-12483.

(38) Tao, J. M.; Perdew, J. P.; Staroverov, V. N.; Scuseria, G. E. Climbing the Density Functional Ladder: Nonempirical MetaGeneralized Gradient Approximation Designed for Molecules and Solids. Phys. Rev. Lett. 2003, 91, 1464011.

(39) Grimme, S.; Antony, J.; Ehrlich, S.; Krieg, H. A Consistent and Accurate $A b$ Initio Parametrization of Density Functional Dispersion Correction (DFT-D) for the 94 Elements H-Pu. J. Chem. Phys. 2010, $132,154104$.

(40) Weigend, F.; Ahlrichs, R. Balanced Basis Sets of Split Valence, Triple Zeta Valence and Quadruple Zeta Valence Quality for H to Rn: Design and Assessment of Accuracy. Phys. Chem. Chem. Phys. 2005, 7, 3297-3305.

(41) Weigend, F. Accurate Coulomb-Fitting Basis Sets for H to Rn. Phys. Chem. Chem. Phys. 2006, 8, 1057-1065.

(42) Becke, A. D.; Johnson, E. R. A Density-Functional Model of the Dispersion Interaction. J. Chem. Phys. 2005, 123, 154101.

(43) Grimme, S.; Ehrlich, S.; Goerigk, L. Effect of the Damping Function in Dispersion Corrected Density Functional Theory. J. Comput. Chem. 2011, 32, 1456-1465. 